\title{
Influence of Hospital Capabilities on Organizational Performance of Mission Hospitals in Kenya
}

\author{
Peter Gaturu ${ }^{1,}$, Daniel Oigo, ${ }^{2,}$ \\ ${ }^{1}$ Departmnet of Business Studies, Jomo Kenyatta University of Agriculture and Technology, Nairobi, Kenya \\ ${ }^{2}$ Department of Business Administration and Management Science, Szent István University, Godollo, Hungary \\ Email address: \\ pmgaturu@gmail.com (P. Gaturu), ogachdniel@gmail.com (D. Oigo) \\ ${ }^{*}$ Corresponding author
}

\section{To cite this article:}

Peter Gaturu, Daniel Oigo. Influence of Hospital Capabilities on Organizational Performance of Mission Hospitals in Kenya. Journal of Business and Economic Development. Vol. 3, No. 1, 2018, pp. 17-21. doi: 10.11648/j.jbed.20180301.13

Received: November 29, 2017; Accepted: December 15, 2017; Published: January 19, 2018

\begin{abstract}
Modern healthcare is characterized by new disease patterns; advanced technologies; unpredictable patients' needs; physical infrastructure and diverse workforce requirements. A hospital is mainly the first point of health care service delivery; and is indispensable in fostering a healthy population. The health sector in Kenya has allowed a diverse non-governmental healthcare sector to develop. Mission hospitals belong to this sector and can significantly improve their service delivery with proper application of strategic management practices. The field of strategic management has undergone a major shift in focus over the last two decades regarding organizational performance variation: from industry's specific to organization-specific factors. Since the inception of strategic management studies in the 1950s; scholars have sought to know determinants that make some organizations more successful than others. This quest has created a bifurcated view, one on industry structure and the other on specific organizational resources.
\end{abstract}

Keywords: Organizational Performance, Hospital Capabilities, Strategic Decisions, Hospital Performance and Mission Hospitals

\section{Introduction}

Resources refer to assets that an organization can access and control. These resources are either tangible or intangible [1]. Organization resources are considered crucial to superior organizational performance; and are defined as assets, knowledge, capabilities and organizational processes [2], [6], [15]. Capabilities refer to an organization's ability to deploy and configure those resources to improve their productivity. [4] posits that capabilities can further be divided into specific skills and specialized capabilities and that it constitutes individual skills, tacit forms of knowledge and social relations that partly forms the culture of an organization.

Technology capability is one of the most sustainable competitive advantages and many studies show a significant relationship between technological capabilities and organizational performance [4]. Technology is broadly seen as an essential component of competitiveness embedded within the structure of the organization, its processes, products, and services. Indeed, technology is believed to improve organizational performance and innovation. Marketing and managerial capabilities are also bases of superior organizational performance.

Mission hospitals must embrace innovative ways in healthcare service delivery, to help them survive and prosper [13]. Operationalization of resource constructs is inconsistent and often controversial [7], [15]. [8], defined the resource constructs as tangible assets, intangible assets and capabilities. To establish the influence of resources on organizational performance, the study examined the influence of hospital capabilities on organizational performance of Mission hospitals in Kenya.

\subsection{Statement of the Problem}

Mission hospitals in SSA are not modernizing and knowledge on their organizational performance is inadequate. Centre for Global Development) attributes this partly to lack of high-level strategic focus. Historically, resources were believed to be important for superior organizational performance that was driven by internal and not external 
factors, and that strategy was a result of a careful evaluation of organizational resources [12]. [15] defined core competences as key value building skills and their influence on organizational performance. Core competencies are capabilities or skills that run through an organization's business and are the basis of an organization's lasting competitive advantage.

In the past, Mission hospitals received unrestricted donations from sponsoring churches abroad, the government posted consultant doctors and nurses and gave essential drugs and vaccines [14]. Today, the support from the government and the sponsoring churches is minimal and this has negatively affected their organizational performance and threatened their very survival. The resources in mission hospitals are also not efficiently utilized, $\mathrm{MOH}$ budget meant to support healthcare across all sectors has been reduced, further cutting the intended financial support to mission hospitals.

The influence of hospital capability on organizational performance of Mission hospitals in Kenya has not been extensively studied. Past research studies were done in Europe and America, and their results were mostly inconsistent. The environment in SSA is different from that of the developed countries, and it is therefore inappropriate to generalize the result findings from these studies. The research study was aimed at establishing the influence of hospital capabilities on organizational performance of mission hospitals in Kenya and the research gap was therefore justified.

\subsection{Study Objective}

The objective of the study was to establish the influence of hospital capabilities on organizational performance of Mission hospitals in Kenya.

\subsection{Hypothesis}

There is a positive significant influence of hospital capabilities on organizational performance of Mission hospitals in Kenya.

\section{Theoretical Orientation}

Historically, resources were important determinants in influencing superior organizational performance. In 1984, Wernerfelt, coined the term Resource-Based View of the firm, and provided a theoretical framework for determining which resources generated sustainable competitive advantage and gave above normal rates of return [4].

\subsection{Resource Based View of the Firm}

Firm resources are the assets, knowledge, organizational processes and capabilities that determine superior organizational performance [15]. These resources are either tangible or intangible [2]. The intangible assets are more firm-specific and difficult to imitate. They confer a superior organizational performance as opposed to tangible resources [10].
The RBV postulates the importance of resources and capabilities as influences of superior organizational performance. [15] defines RBV as a method of identifying firms' strategic advantages based on its distinct combination of assets, skills, and capabilities. RBV argues that an organization's competitive advantage comes from its resources and capabilities [4]. The theory endeavors to determine the value of an organization's resources and capabilities and how organizations can acquire, maintain, deploy and develop resources in a manner capable of establishing and maintaining a competitive advantage [4]. Resources of the firm are valuable if they meet needs of the customers better than available alternatives, are scarce, drive key portion of a firms' profit and are durable.

Arguments on industry structural characteristics have become less relevant, while organizational resources are becoming the basis upon which organizations compete [12]. Indeed, the extant literature shows that organizational characteristics alone cannot explain variance in organizational performance sometimes in organizations operating in the same industry [13]. [11], posits that the resources and capabilities enable sustainable competitive advantage if they are rare, valuable and inimitable, and nonsustainable. The RBV holds that superior organizational performance is driven by internal and not external factors and that strategy is a result of a careful evaluation of organizational resources [14].

The main argument in RBV is that a firm's competitive advantage comes from its resources and capabilities rather than its products and markets [4]. This view, therefore, endeavors to determine the value of organizations' resources and capabilities and how organizations can acquire, maintain, deploy and develop resources in a manner capable of establishing and maintaining competitive advantage. Organizational capabilities are not specific inputs [15], but skills, indeed the firm's ability to configure and deploy resources to improve organizational performance and achieve its strategic goals.

\subsection{Empirical Orientation on Hospital Capabilities}

[8], posit that in the quest to understand the determinants of firm performance, two views have been created; one supporting the industry structure characteristics and the other supporting firm-specific resources. In their study on firm factors, industry structure, and performance variation, they found that resources are more important than industry structure variables in explaining performance variation. This has indeed created two competing theories of performance variation in strategic management with important implications for management practice; that is if resources are the most important determinants of performance, should managers then be concerned about industry structure? And if industry structure is the prime determinant of performance, how much attention should be paid to resources?

[17], in a study of dynamic capabilities and firm performance in financial crisis found that adoption of new technologies and new business models by organizations are 
more likely during the recession due to lower opportunity costs. In a study by [18], on marketing strategy determinants of export performance: a meta-analysis, found that although many marketing strategy variables demonstrated positive effects on an overall export performance, the relationship is not always significant, and that time of study, geographical focus and product type had limited impact on export performance. [16], did a study on service firm capabilities and performance: contingent analysis of customer contact and focused on organizational, marketing, managerial and service quality capabilities. The study found a positive relationship between all these variables and concluded that service management should differ depending on the level of customer contact that service firm require.

Hospital resources can be assessed through different indicators. Among these indicators are the number of beds, number of doctors and number of Nurses. The capacity can also be surveyed through the number of available equipment and number of surgeries done in the hospitals. [9] in a study on a conceptual framework to analyze hospital competitiveness found that quality and delivery are the most important determinants of hospital performance. [16], found that resource based quality improvement is a strategic determinant of superior organizational outcome in hospital performance; intended to improve both the quality of the product and image of the hospital. Construction of physicians' office buildings next to the hospital, investment in high technology diagnostic equipment, highly trained doctors, nurses and other technicians, provision of adequate hospital beds and high technology laboratories were some of the strategic determinants identified in this study.

\section{Data Analysis Methodology}

Descriptive statistics, Pearson correlation and t-test were used to analyze data as the study was both qualitative and quantitative. The analysis of research hypotheses was done with the help of SPSS Version 22 and advance excel. Correlation and linear regression (OLS) were used to analyze the relationship between variables. Research hypothesis in this research study was analyzed at $95 \%$ level of significance.

\section{Results from the Findings}

The researcher wanted to establish the influence of hospital capabilities on organizational performance of mission hospitals in Kenya. The findings from the data collected revealed the following; Asked about the extent to which technology assist in the provision of healthcare services at the hospital, majority of the respondents $(80.8 \%)$ said that it is to a very greater extent while $16.4 \%$ said that it is to a moderate extent. The majority $(73.3 \%)$ of the respondents said that the hospital ensures achievement of knowledge, managerial and operative skills while $24 \%$ said it is to a moderately less extent. A small percentage of the respondents said the hospital does not ensure knowledge, management and operative skills at all. On the other hand, most of the respondents $(68.5 \%)$ agreed that said that strategic plan ensures achievement of hospitals market position and availability of market skills. $24 \%$ said it's to a moderate extent while a small percentage of $7.5 \%$ of the remaining respondents said that it is to a less extent.

Table 1. Response on the Influence of Hospital Capabilities on Performance.

\begin{tabular}{|c|c|c|c|c|c|}
\hline & Very Greater Extent & Greater Extent & Moderate Extent & Less Extent & Not at all \\
\hline $\begin{array}{l}\text { Extent to which technology assist in provision of } \\
\text { healthcare services at hospital }\end{array}$ & $52(35.6 \%)$ & $66(45.2 \%)$ & $24(16.4 \%)$ & 0 & $4(2.7 \%)$ \\
\hline $\begin{array}{l}\text { Extent to which the hospital ensures achievement of } \\
\text { knowledge, managerial and operative skills }\end{array}$ & $22(15.1 \%)$ & $85(58.2 \%)$ & $35(24.0 \%)$ & 0 & $4(2.7 \%)$ \\
\hline $\begin{array}{l}\text { Extent to which the strategic plan ensures } \\
\text { achievement of hospitals market position and } \\
\text { availability of market skills }\end{array}$ & $33(22.6 \%)$ & $67(45.9 \%)$ & $35(24.0 \%)$ & $11(7.5 \%)$ & 0 \\
\hline
\end{tabular}

The findings are like those of [5], who did a study on dynamic capabilities and organizational performance in a financial crisis. He found out that adoption of new technologies and new business models by organizations are more likely during a recession due to lower opportunity costs. A similar study by [6]. in their study on marketing strategy determinants of export performance: a meta-analysis found out that although many marketing strategy variables demonstrated positive effects on an overall export performance, the relationship is not always significant, and that time of study, geographical focus and product type had limited impact on export performance. [13], did a related study on service firm capabilities and performance: contingent analysis of customer contact and focused on organizational, marketing, managerial and service quality capabilities. The study found a positive relationship between all these variables and concluded that service management should differ depending on the level of customer contact that service firm require.

Botswana has invested considerably in building hospitals across the country, resulting in high physical access to health care services. However, the capacity of the hospitals to deliver healthcare services is limited by inadequate resources; and there are significant challenges in the quality of care. The researchers suggested that public hospitals in Botswana are under pressure to improve their organizational performance and that hospital performance is affected by the availability of resources. The hospitals' organizational performance influences the performance of the entire healthcare sector; and worldwide, there is pressure on hospitals to improve their organization performance. While this study focused on public hospitals in Botswana; mission 
hospitals in Kenya are experiencing the same pressure; the need to improve their organizational performance. This is based on their huge contribution $(43 \%)$ of healthcare service delivery in the country.

\section{Descriptive Statistics}

The descriptive statistics of interest to the researcher included correlations and the t-test. The findings from the field were as shown below;

\section{Correlations}

The researcher wanted to establish if there existed a linear relationship between hospital capabilities and organizational performance of mission hospitals. The findings from the field were as shown below;

Table 2. Correlations Matrix.

\begin{tabular}{llll}
\hline & & Hospital Capabilities & Organizational Performance \\
\hline & Pearson Correlation & 1 & $.544^{* *}$ \\
Hospital Capabilities & Sig. (2-tailed) & .000 & .002 \\
& $\mathrm{~N}$ & 146 & 146 \\
Organizational Performance & Pearson Correlation & $.544^{* *}$ & 1 \\
& Sig. (2-tailed) & .000 & .000 \\
& $\mathrm{~N}$ & 146 & 146 \\
\hline
\end{tabular}

The findings revealed that there is a strong positive correlation between hospital capabilities and organizational performance of mission hospitals in Kenya. This was according to the Pearson correlation coefficient of 0.544 . This is indeed in line with the RBV of the firm that holds that superior organizational performance is driven by internal and not external factors and that strategy is a result of a careful evaluation of organizational resources.

\section{Test of Hypothesis}

The researcher tried to establish if hospital capabilities had a significant influence on the organizational performance of mission hospitals in Kenya. The conclusion from the findings of the study established the following;

Table 3. One-Sample Statistics.

\begin{tabular}{llll}
\hline $\mathbf{N}$ & Mean & Std. Deviation & Std. Error Mean \\
\hline 146 & 4.7283 & 1.37186 & .11354 \\
142 & 6.8662 & 18.70572 & 1.56975 \\
\hline
\end{tabular}

The table above shows a mean of 4.7283 . The mean shows that the frequency within which a hospital bed is occupied by another patient in a month is between 10-12 patients. This

shows that the number of patients visiting the hospital is high.

Table 4. One-Sample Test.

\begin{tabular}{|c|c|c|c|c|c|c|}
\hline & \multicolumn{6}{|c|}{ Test Value $=0$} \\
\hline & \multirow{2}{*}{$\mathbf{T}$} & \multirow{2}{*}{ df } & \multirow{2}{*}{ Sig. (2-tailed) } & \multirow{2}{*}{ Mean Difference } & \multicolumn{2}{|c|}{ 95\% Confidence Interval of the Difference } \\
\hline & & & & & Lower & Upper \\
\hline Hospital Capability & 41.646 & 145 & .000 & 4.72831 & 4.5039 & 4.9527 \\
\hline $\begin{array}{l}\text { Frequency at which hospital bed is } \\
\text { occupied by different patient in a month }\end{array}$ & 4.374 & 141 & .000 & 6.86620 & 3.7629 & 9.9695 \\
\hline
\end{tabular}

The findings from the table above show a sig. value of 0.00 which is small than 0.05 . This leads us to accept the null hypothesis which states that there is a positive significant influence of hospital capabilities on organizational performance of mission hospitals in Kenya. We, therefore, conclude that there is a significance difference between the means of hospital capabilities and organizational performance. Therefore, we conclude that there is a significant difference between hospital capabilities and organizational performance.

In a study by [8] on firm factors; industry structure and performance variation found that resources were more important than industry structure variables in explaining variations in organizational performance. [16]. in a study on service capabilities and organizational performance found a positive relationship between the variables that included organizational; marketing; managerial and service quality capabilities.

\section{Conclusions}

Asked about the extent to which technology assist in the provision of healthcare services at the hospital, most of the respondents said that it is to a very greater extent while others said that it is to a moderate extent. Most of the respondents also said that the hospital ensures achievement of knowledge, managerial and operative skills while a small percentage said it is to a moderately less extent. A small percentage of the respondents said the hospital does not ensure knowledge, management and operative skills at all. On the other hand, most of the respondents agreed to a greater extent that said that strategic plan ensures achievement of hospitals market position and availability of market skills. Small percentages of the remaining respondents said that it's to a moderate extent. 


\section{Recommendations}

On hospital capabilities on the performance of mission hospitals in Kenya, the study concluded that it is to a very greater extent. On the average length of hospital stay for patients between admission and discharge the study revealed a higher percentage of the respondents said that the length of time in hospital stay is between 4-7 days. In addition, the study also concluded that the average waiting time for an outpatient before they are attended to was less than 30 minutes. On the frequency at which hospital bed is occupied by a different patient in a month, the study found out that the hospital bed is occupied by between 1-6 patients in a month. In addition to that, the other respondents said that the hospital bed handles between 10-12 patients per bed. Additionally, some said that the bed handles 13-15 patients per bed while the remaining respondents said that the hospital bed is occupied by 7-9 patients per month.

The study also identified some challenges faced by the hospital in the adoption of strategic management. One of the most critical challenges identified by the respondents was financing. Respondents said that they don't have enough finances for strategic management. Another main challenge that was identified by the study included frequent changes in management. This was according to $75.3 \%$ of the respondents. Most of the other respondents said that they are faced with technological challenges; technological changes in health management. Some of the respondents said that they face resistance to change as a challenge; while other respondents said that the number of employee turnover is high. Decision-making process is also slow since the chain of command is long. Other respondents feel that there is a lack of support and cooperation by top management.

\section{References}

[1] Adams et. al (2007). Research Methods for Graduate Business and Social Science Students. Los Angeles, USA: Sage.

[2] Barney JB, Arikan AM. 2002. The resource-based view: origins and implications. In Handbook of Strategic Management, Hitt MA, Freeman RE, Harrison JS (eds). Blackwell: Oxford, UK, 124-188. Barney JB.

[3] Church Health Association of Kenya (2000). The Mission of the Church in Health Care.

[4] Claver-Cortés, E., Pertusa-Ortega, E. M., \& Molina-Azorín, J.
F. (2012). Characteristics of organizational structure relating to hybrid competitive strategy: Implications for performance. Journal of Business Research, 65(7), 993-1002.

[5] David g. Hoopes, Tammy. Madsen and Gordon Walker. (2003). Guest editors' introduction to the special issue: why is there a resource-based view? toward a theory of competitive heterogeneity. Strategic Management Journal Strat. Mgmt. J., 24: 889-902 (2003) Published online in Wiley Inter Science (www.interscience.wiley.com). DOI: 10.1002/smj.356.

[6] Dibrell, C., Craig, J. \& Neubaum, D. (2007). Linking the formal strategic planning process, planning flexibility, and innovativeness to firm performance. Journal of Business Research, 67 (4).

[7] Eiriz, V., Barbosa, N. \& Figueiredo, J. (2010). A conceptual framework to analyze hospital competitiveness. The service Industrial Journal, 30(3), 437-448.

[8] Galbreath, J., \& Galvin, P. (2008). Firm factors, industry structure and performance variation: New empirical evidence to a classic debate. Journal of Business Research, 61, 109-117.

[9] Gautam Ahuja and Riitta Katila (2004). where do resources come from? The role of idiosyncratic situations. Strategic Management Journal Strat. Mgmt. J., 25: 887-907 (2004) Published online in Wiley Inter Science (www.interscience.wiley.com). DOI: 10.1002/smj.401

[10] Johnson, G., Scholes, K., \& Whittington, R. (2005). Exploring Corporate Strategy. New Delhi, India: Pearson Education Ltd.

[11] Joseph E. Coombs and Paul E. Bierly III (2006). Measuring technological capability and performance. volume 36 , issue 4 aodheen o'donnell, audrey gilmore, david carson and darryl cummins.

[12] Karabag, S. F. (2008). Effects of strategy and industry on firm performance: An examination on Turkish leading manufacturing companies (in Turkish). (PhD Dissertation). Adana: The Publications of the Social Science Institute, Çukurova University.

[13] Ortega, M. J. R. (2010). Competitive strategies and firm performance: Technological capabilities' moderating roles. Journal of Business Research, 63(12), 1273-1281.

[14] Salamon, S. D., \& Robinson, S. L. (2008). Trust that binds: The impact of collective felt trust on organizational performance. Journal of Applied Psychology, 93(3), 593-601. http://dx.doi.org/10.1037/0021-9010.93.3.593.

[15] Wright M, Ketchen DJ. 2001. The resource based view of the firm: ten years after 1991. Journal of Management 27: 625641. 